\title{
TRADUCCIÓN Y TRADUCCIÓN DE SÍ EN GEORGES-ARTHUR GOLDSCHMIDT ${ }^{1}$
}

\author{
Niklas Bornhauser \\ Universidad Andrés Bello \\ Santiago, Chile \\ niklas.bornhauser@gmail.com \\ Gianfranco Cattaneo \\ Universidad Andrés Bello \\ Santiago, Chile \\ g.cataneo@unab.cl
}

\section{RESUMEN / ABSTRACT}

La obra de Georges Arthur Goldschmidt, a pesar de su amplio reconocimiento, sobre todo en Alemania y Francia, sigue siendo desconocida en los países de habla hispana. Ello parece una omisión potencialmente productiva, ya que sus textos no solamente ofrecen una lúcida reflexión acerca de la relación entre las lenguas y el pensar, sino que además problematizan cómo la traducción afecta al pensar. Se discute la presencia de la traducción en tanto práctica y teoría en algunos textos del autor, considerando especialmente la pregunta por el trauma.

PALABRAS ClAVE: traducción, escritura, psicoanálisis, lengua, autobiografía.

\section{TRANSLATION AND SELF-TRANSLATION IN GEORGES-ARTHUR GOLDSCHMIDT}

The work of Georges Arthur Goldschmidt, despite its widespread recognition, especially in Germany and France, remains unknown in Spanish-speaking countries. This seems a potentially productive omission, since his texts not only offer a lucid reflection on the relationship between languages and thinking, but they also problematize how translation affects thinking.

1 Este texto fue escrito en el marco del proyecto FONDECYT Regular 1171146 "Lengua, traducción, pensamiento: Hegel - Freud - Hamacher". 
The presence of translation is discussed as practice and theory in some texts of the author, considering specially the question concerning trauma.

KEYWORDS: translation, writing, psychoanalysis, language, autobiography.

Recepción: 05/04/2018

Aprobación: 10/05/2018

\section{INTRODUCCIÓN}

Georges-Arthur Goldschmidt es un escritor, traductor, ensayista y profesor de alemán, nacido el 2 de mayo de 1928 en Reinbek cerca de Hamburg. En el ámbito de habla alemana y francesa goza de un considerable reconocimiento, que se expresa en distinciones tales como el Deutscher Sprachpreis (1991), el Geschwister-Scholl-Preis (1991), el Ludwig-Börne-Preis (1999), la Goethe-Medalle (2002), el Prix France Culture (2004) y el Sigmund-FreudKulturpreis (2015), entre otros. Sin embargo, salvo en círculos especializados y reducidos, sigue siendo prácticamente un desconocido para la comunidad hispanoparlante. Al menos dos razones pueden esgrimirse al respecto. La primera, parafraseando lo que Andrés Claro en Las vasijas quebradas ha denominado "nuestra condición latinoamericana" (2012), refiere a lo que restringe, al mismo tiempo que potencia, el pensamiento en castellano. Se trata en ésta de una doble determinación, consistente en la dependencia, del costado de la lectura, de traducciones a nuestra lengua, y del lado de la escritura, del pensamiento, de la producción literaria, de la extraordinaria dificultad de escribir en otras lenguas, asociada a la incertidumbre acerca del estatuto del pensamiento en castellano. El relativo desconocimiento de Goldschmidt se explicaría, entonces, por la casi inexistente traducción al castellano de sus obras: hasta la fecha, únicamente se conoce la traducción de Cuando Freud vio la mar, editada por Metales Pesados (Goldschmidt 2017). La segunda razón, que hace eco del problema de la traducción, es que los escritos de Goldschmidt corresponden, al menos en principio, a una tradición profundamente europea, perteneciente a la Europa de la primera mitad el siglo XX, referida al exilio, el sometimiento y la sujeción. Claramente, estas temáticas no son originarias ni exclusivas del viejo continente. Pero, en la producción escritural de Goldschmidt, son desarrolladas de un modo predominantemente "eurocéntrico", al remitir esas experiencias propias de la historia europea reciente, como el surgimiento del nacionalsocialismo y la shoa, al tránsito entre dos lenguas concretas: el alemán y el francés. Esto 
permite comprender que su trabajo académico y ensayístico haya estado fuertemente centrado en pensar el espacio del entre dos lenguas y en explorar las dificultades del pasaje de una lengua a otra.

Aun cuando las coordenadas históricas y la sujeción idiomática parecieran identificar a Georges-Arthur Goldschmidt como un escritor típicamente europeo -y, además, perteneciente al siglo pasado-, en lo que sigue queremos mostrar que la lectura de sus textos desoculta una dimensión transversal, contemporánea, ajena a las inscripciones geopolíticas particulares. Porque la pertenencia a una lengua no es equiparable a cualquier otro modo de inclusión o de pertenencia a un pueblo, a un Estado o a una nación -y lo mismo vale para los respectivos modos de exclusión. Lo que cuenta y lo que resta, veremos, es la lengua. Por ello, lo que une y separa a las lenguas, inaugura un espacio, al mismo tiempo vacío y sobredeterminado, que no pertenece a ninguna de ellas. Inapropiable, es un espacio en que el hombre se inventa -y es inventado- en la lengua, expresando con ello su propia extranjería y extrañeza. Como afirma Goldschmidt, dado que toda lengua es traducción o posibilidad de traducción, y que lo más característico e inconfundible de la lengua es que ella balbucea, "resulta sorprendente que una lengua se exprese, ciertamente, empero ella no lo ve, en suma, sino cuando se topa con otra lengua, cuando su 〈intensidad〉 se interrumpe de golpe-como si ella estuviera hecha alrededor de lo que no marcha en ella, pero que solamente se le aparece en la traducción: como si otra lengua le revelará su inconsciente" $(2017,103)$.

En lo que sigue, no se trata solo de "dar a conocer" parte de la producción escrita de Georges-Arthur Goldschmidt, sino de mostrar, con él, en toda su radicalidad, los efectos de la carencia de lengua, la falta de esta, la Sprachlosigkeit, y cómo ésta se convierte en fuente y motor de la búsqueda de otras palabras, otros modos de decir, en otras lenguas.

\section{DE GOLPE, EL ENTRE-LENGUAS}

Como señala Michaela Holdenried (1997), las novelas de Goldschmidt, desde Un corps dérisoire (1971) hasta La Joie du passeur (2013), tienen, prácticamente sin excepción, un marcado carácter autobiográfico. Una y otra vez, el autor elabora en ellas la experiencia del destierro y del exilio. La elaboración, siempre insuficiente, de dicha experiencia, no resulta determinante para lo que podría llamarse, en principio y de manera tentativa, su nivel de "contenido", pues las tramas narrativas giran en torno al abandono, el desarraigo y la pérdida, 
sino que compromete fuertemente lo que, recurriendo a esta misma distinción, sería su registro "formal". Sus primeros libros fueron escritos precisamente en su nueva lengua, el francés, para luego ser traducidos al alemán (por Peter Handke, entre otros): Un corps dérisoire (1971), Le Fidibus (1971), Le miroir quotidien (1981), Un jardin en Allemagne (1986), en el cual describe su infancia transcurrida en la alta burguesía en Reinbek, una pequeña ciudad cerca de Hamburgo, Narcisse puni (1989) y La forêt interrompue (1991). En paralelo a la escritura de La forêt interrompue, Goldschmidt trabajó en Die Absonderung (1991), escrito en alemán, probablemente su libro más conocido, por el cual recibirá el mismo año el premio Hermanos Scholl. En él, tal como indica su título -literalmente: el apartamiento, el poner de lado-, Goldschmidt narra los cinco años en que residió en un internado en los Alpes franceses. Die Aussetzung (1996) -la exposición, la suspensión-, que anuda y continúa el relato iniciado en Die Absonderung, junto a Die Befreiung (2007) -la liberación-, que puede ser leído como un relato de los años de pubertad en la Francia de 1944, conforman lo que ha sido distinguido como la trilogía de Saboya. A su vez, los textos ensayísticos en su totalidad han sido escritos en francés: Molière ou la liberté mise à un (1973), Nietzsche pour tous et pour personne (1974), Jean-Jacques Rousseau, ou, L'esprit de solitude (1978), Peter Handke (1988), Quand Freud voit la mer (1988), Quand Freud attend le verbe (1996), La matière de l'écriture (1997), En présence du Dieu absent (2001). En cuanto a las traducciones, salvo dos excepciones -la novela Alcyon de Pierre Herbart y su relato, aún no publicado, titulado "Das goldene Zeitalter"-, éstas han sido realizadas del francés al alemán: entre otras, 27 textos de Peter Handke, Das Schlo $\beta$ [El castillo] y Der Proze $\beta$ [El proceso] de Franz Kafka, Die Leiden des jungen Werther [Las tribulaciones del joven Werther] y Briefe aus der Schweiz [Cartas desde Suiza] de Johann Wolfgang von Goethe, Also sprach Zarathustra [Así hablaba Zaratustra] de Friedrich Nietzsche.

El abandono forzoso de Alemania, relatado de manera tan sobria como impactante en las últimas páginas de Ein Garten in Deutschland, no solo implicó la pérdida de sus padres, sino la pérdida de la patria, del Vaterland $\mathrm{y}$, asimismo, la pérdida de la lengua materna, Muttersprache. Si bien, como ha señalado Dieter Lamping (1995), los cambios de lengua provocados por el exilio no deben ser comprendidos exclusivamente desde la vertiente negativa, es decir, como la pérdida de la lengua materna y de las construcciones identitarias asociadas, sino que también, en principio, como aquello que habilita a la posibilidad de acceder a creaciones literarias de una autonomía 
extraordinaria, en el caso de Goldschmidt la lengua materna, el alemán, quedó marcada como una lengua prohibida, determinada irreversiblemente por los acontecimientos que ya arrojaban sus sombras sobre Europa. Martin Rector (1995) ha corroborado que en sus relatos encontramos una especie de "compulsión a la repetición", una suerte de coerción, asociada a la pulsión de muerte, que insiste incansablemente en volver sobre la experiencia infantil del exilio, del envío a otro país, del abandono de los padres, y del padecimiento, en una tierra extraña, de la rígida disciplina de las instituciones pedagógicas y el maltrato de parte de los compañeros. Si, como dice Goldschmidt en Cuando Freud vio la mar $(2017,33)$, entregándose a un juego que también es posible en castellano, la lengua humana es como la mar, el juego que permite la homofonía francesa entre mer y mère el alemán no lo conoce. Y, sin embargo, existe un desvío que le permiten llegar hasta allí. Lo que muestran sus textos es que la prohibición que cae sobre la madre recae de vuelta sobre el cuerpo [der Leib]. Es como si la lengua alemana contuviera en ella misma "la marejada originaria del mar", como si conservara el movimiento del oleaje en la respiración que el caminante en la playa modela según el golpear de las olas. La lengua alemana se construye "sobre la elevación y declinación" de la caja torácica, sobre el ir y venir en el espacio, que no es otra cosa que "el célebre Fort-Da del niño en Más allá del principio del placer" (Ibid.). Si como afirma Goldschmidt, la lengua alemana parte desde el cuerpo, si está inextirpablemente implantada en él, hasta el punto de que la totalidad de la lengua se conforma desde un emplazamiento del cuerpo en el espacio, este espacio, desde donde la lengua comienza, es, sin embargo, ya un desplazamiento. Un entramado imposible de desembrollar. Como una especie de tragedia común, la marca que cae sobre la lengua materna es también la que cae sobre el acceso inmediato al cuerpo. La pérdida de la lengua materna trae consigo la pérdida de la expresión espontánea y la reacción natural e inmediata a través de la lengua. Porque es su pérdida lo que hace que una lengua sea, tal, "materna". Lo que vuelve, entonces, "materna" a una lengua, como sostiene Barbara Cassin (2016), es la posibilidad que entrega esta de inventar, de hacer con ella y producirla como puesta en práctica antes que el servirse de ella como totalidad cerrada, idéntica a sí (Cassin 2013, pp. 78-79).

Segregado y separado [abgesondert], expuesto y abandonado [ausgesetzt ] por el alemán, el francés se convierte para Goldschmidt en la lengua que lo acoge, rescata y protege. Mediante la escritura autobiográfica, construye en ella una morada, por muy transitoria y precaria que sea, en la que puede siquiera pensar en elaborar el trauma de la pérdida y de la violencia originaria 
que se asoma a través de ella. Rainer Guldin (2009) ha sistematizado algunos comentarios del propio Goldschmidt que resultan esclarecedores respecto de este punto. Así, por ejemplo, el año 2001 en un diálogo con Ina Hartwig, al preguntársele por qué habría escrito algunos de sus libros en alemán y otros en francés, Goldschmidt contesta: "En mi infancia me era imposible escribir en alemán, porque había sido expulsado [verstoßen] de esta lengua" (21). En el prefacio de la versión en alemán de su autobiografía La traversée des fleuves, cuya traducción al alemán, Über die Flüsse, fue hecha por él mismo, dice: "Fue necesario atravesar el francés, con tal de restablecerle al alemán su inocencia, al menos la posibilidad de encontrar acceso a él mediante la escritura: el francés [...] es el único autorizado a describir una infancia alemana $[\ldots]$ saltar sobre el abismo que la historia ha cavado en medio de la lengua alemana [...]; lo que se cuenta es pasado por el tamiz de la lengua en la que no es vivido" (8). Jürg Altwegg (2008), en "Josef K., das war ich", a propósito de la publicación de Die Faust im Mund, destaca cómo en junio de 1946, paseando por Annecy, Goldschmidt encuentra en una librería de libros usados un ejemplar del Zarathustra, editado especialmente para la Wehrmacht como parte de la lamentable apropiación y desfiguración del pensamiento de Nietzsche. Mientras que el librero apenas disimulaba su felicidad por poder deshacerse del libro, el comprador, avergonzado, lo escondía bajo su suéter. En un banco, a medio camino entre la ciudad y el lago, comenzó a leer y descubrió un alemán "como si fuera de una traducción de la Bibliahecha por Lutero", que le evocaba la prédica protestante, habitual en la casa de su padre convertido al protestantismo. Para Goldschmidt, por un lado, era "la lengua de mi infancia"; pero también, al mismo tiempo, la lengua que dejaba en claro: "Tú no eres uno de nosotros". Se ve, entonces, que el paso de una lengua a otra-que obedece, por un lado, a la expulsión forzosa de parte de una fuerza activa, y por el otro, a una aspiración o un anhelo, un Streben hacia-, que pareciera prometer la posibilidad de elaborar la pérdida sufrida, implica, al mismo tiempo, sumar otras pérdidas, otros quebrantos, otras quiebras. Dicho paso, siguiendo a Andrés Claro (2011), si es que alguna vez es realizado, no ha de ser pensado, acaso al modo de la metáfora fluvial o un traspaso continuo y lineal, en el cual algo es transportado a otro lado sin sufrir alteraciones ni percances, sino como una suspensión, una cesación, enajenante y turbadora, que introduce la discontinuidad y la posibilidad del futur antérieur, y con ello la posibilidad de historizar y de narrar, en la temporalidad subjetiva. En cierto modo, el descentramiento producido por la constitución subjetiva en el lenguaje, de la cual la constitución en la lengua es una variante a precisar, 
se convierte en el antecedente de una dislocación segunda, consistente en el desarraigo de la lengua originaria, que precisamente viene a desocultar el carácter precario y protésico de la inserción en la lengua.

La dinámica de ida y vuelta, el vaivén entre el alemán y el francés interroga el movimiento mismo de la traducción. En Goldschmidt, la traducción, antes que un gesto técnico, una acción mecánica y desimplicada, es traducción de sí o autotraducción. Dieter Lamping (1992) ha subrayado un procedimiento similar en algunos poetas (Stefan George, Rainer Maria Rilke, Hans Magnus Enzensberger) y escritores (Klaus Mann y Robert Neumann), distinguiendo, para cada caso, si la traducción va de la lengua materna a una lengua extranjera, o al revés. A diferencia de lo propuesto por Lamping, en Goldschmidt, partiendo de sus propios escritos, es posible construir una hipótesis comprensiva acerca de los motivos que lo animaron a emprender una traducción de sí caracterizada por el desarraigo, y en la que la sensación de ajenidad es parte fundamental del poder creador del acto lingüístico. Esta orientación, opuesta a la Geborgenheit, a la que aspiraba el historicismo romántico, es resumida por Stefan Willer cuando afirma que "los trabajos de prosa referidos entre sí de manera múltiple, que se reflejan y repiten, tratan el problema del cambio de lengua como una traducción que interviene la vida" (2007: 268).

Si la hipótesis en cuestión se edifica en torno al problema del trauma, éste, como enseña el psicoanálisis, debe considerarse en dos tiempos: primero, la expulsión, violenta y repentina, padecida pasivamente, del supuesto idilio paradisiaco en que es convertido retroactivamente, nachträglich, la lengua materna; segundo, la violencia ejercida sobre el cuerpo, una vez instalado, por muy precariamente que sea, en la nueva lengua y que viene a actualizar la violencia originaria que opera en la Setzung o posición o emplazamiento primordial del sujeto hablante. Además de que la golpiza como tema atraviesa prácticamente todos los textos de Goldschmidt, la experiencia de la Zweisprachigkeit o bilingüisticidad ocurre para él no tan solo súbitamente, de improviso, sino "de golpe" [mit einem Schlag]. Como advierte Willer: "[e]ra como si todo lo hasta la fecha escuchado fluyera hacia esa palabra singular 'flocons', tal como si ahí se realizara de una vez toda la lengua; se había desarrollado una nueva lengua alrededor de él tal como si fuera una complexión del espacio"(50). Parece tratarse de la misma nieve que luego golpeará al joven Georges-Arthur, convertida en "bolas de nieve amasadas hasta la dureza" (Ibid). 
La escritura autobiográfica de Goldschmidt está atravesada por una secuencia infinita, a ratos compulsiva, de golpes, azotes y castigos. Ina Hartwig, en Die Obsession der Schläge, refiere, al respecto, verdaderos rituales de castigo físico [Züchtigung], narrados con una claridad asombrosa en Die Absonderung (1991), Der unterbrochene Wald (1992), Die Aussetzung (1996) y Die Befreiung (2007). En ellos relata los reiterados castigos propinados por su institutriz, en el culo desnudo y en las puntas de los dedos, con férulas o varas que él mismo con anterioridad tenía que ir a buscar y cortar en el bosque. Ahora bien, tal como se desprende de la narración, los golpes, en lugar de destruir al joven Georges-Arthur, más bien lo habrían salvado. Los castigos corporales, aplicados con tanta sistematicidad como crueldad, habrían subjetivado al joven muchacho, rescatándolo de padecer un destino más terrible - la pérdida de la razón equivalente a la aniquilación subjetiva. El dolor físico, causado por el violento disciplinamiento del cuerpo, según Goldschmidt, habría ocultado un dolor no solo mayor, sino insalvable, asociado nuevamente a otro castigo: la nostalgia [Heimweh], la añoranza [Sehnsucht], el anhelo fervoroso de intentar recuperar lo originariamente perdido. Pero esta lectura de la marca sobre el cuerpo no salta inmediatamente a la vista, ya que, como los castigos no obedecían por lo general a transgresiones detectables en el presente más cercano, parecieran purgar una falta cometida en la temprana infancia. Ina Hartwig, en Das Geheimfach ist offen (2012), ha recopilado una serie de recuerdos, escenas y pasajes que subrayan esta idea.

"Para los niños", dice Goldschmidt, "el ser golpeado [Geschlagenwerden] puede ser una espantosa salvación de la propia identidad, una delimitación de sí mismo, de la cual extraigo la prueba que existo. Freud probablemente lo haya entendido así. Si es causada este tipo de excitación, para un mancebo es algo que no resulta comprensible [verstehen]. No es asible [begreifen]. $\mathrm{Y}$ esta incomprensión puede desconcertar y estremecer profundamente a un niño. ¿Cómo es que el castigo me excita? Este es un mundo al revés. A través de ello, todos los conceptos de autoridad, todo pensamiento referido a algún tipo de autoridad es socavado. La personalidad del niño se constituye en medio de esta confusión" $(2005,147)$. Esta confusión es lo que, en opinión de Freud, perfila la cuestión del lado de la fantasía - una distinción que en Goldschmidt no parece estar del todo clara, pues una cosa es "ser golpeado" y otra, muy distinta, es la fantasía de ser pegado. Tal como destaca Lacan, la fantasía Pegan a un niño [Ein Kind wird geschlagen] pivotea sobre el elemento instrumental, vara o látigo, que, al modo de un elemento desprendido o desplazado del instinto sexual, opera como el significante de la fantasía. La 
existencia del látigo es la que transfiere la autoridad al castigador y lo que demuestra, a su vez, que es el carácter simbólico de la fantasía lo que está erotizado desde el origen. Porque el placer que se obtiene de la fantasía se desprende del hecho de que es inaplicable en la realidad. La fantasía propone un texto y no una acción. Si tiene que ver con un proceso de individuación, con la respuesta de un sujeto al llamado de la existencia simbólica mediante la distinción con el hermano rival, se debe a que determina una enunciación que señala, para ese sujeto, su lugar en un orden simbólico que no tiene ni comienzo ni fin. Por esta razón es que la sexualidad, al estar capturada y articulada, desde el comienzo, en una cadena significante, se organiza en torno a aquel elemento perverso. Como un secreto que permanece tal incluso para quien lo guarda o lo confiesa, una solución fantasmática es requerida para que el mensaje de ser pegado/amado, que vehicula la fantasía, toque al sujeto como algo distinto que el silencio puro del apabullamiento del que gozaría exclusivamente el educador. La ley de la Schläge, como la llama Lacan, determina, mediante un mismo gesto, el ingreso del sujeto en el dominio del deseo y su anulación significante, a partir de la cual podrá establecerse como diferencia. Lo que lo tacha y le entrega un instrumento con el que operar, lo destina a no ser otra cosa más que un punto de pasaje. Porque el significante reconoce al sujeto ${ }_{2}$ al mismo tiempo que hace caer sobre él la inter-dicción, que lo consagra y valoriza en cuanto deseo, a la vez que lo profana. Este aspecto degradante ${ }_{2}$ implica un reconocimiento y prohíbe la relación inmediata y exclusiva del sujeto con la autoridad paterna; es una afirmación que, al poner en juego el deseo del sujeto y el deseo del legislador, es al mismo tiempo una separación (Lacan 2007, pp. 250-256). De esta forma, podemos pensar que en Goldschmidt, la escritura de sí anuda, de manera repetitiva, un sentimiento de culpa, asociado a la curiosidad sexual, al descubrimiento, siniestro y profanatorio, de la diferencia sexual y de la propia homosexualidad, y a la separación de los padres, que quedaron atrás en la Alemania natal. Pero no hay que olvidar, para considerar adecuadamente la repetición, que la culpa, como mostró Freud, también es deuda [Schuld]. La enmarañada travesía de Goldschmidt, trazada por sucesivos movimientos se suspende, de ahí en adelante, en un entre en el que no se puede estar pero del que hay que rendir cuentas; una especie de espacio intermedio -el zwischen o in between- entre dos orillas que solo se tornan pensables a partir de esta efímera existencia intermedia. En un ensayo, titulado precisamente Una chaise à deux dosiers, Goldschmidt alude al entre-deux-langues, a saber, el hecho de que ninguna lengua dice exactamente lo mismo que otra, que 
una lengua no puede ocupar el lugar de otra, que no pueden superponerse dos lenguas, que no hay biunivocidad perfecta entre lenguas, sino siempre habrá, inevitablemente, un entre insalvable. Si bien lo anterior, retomando una línea argumentativa ya esbozada, admite una lectura positiva, a saber, aquella que sostiene que quien vive entre varias lenguas puede ser hombre de múltiples maneras, al mismo tiempo, y esta sería la respectiva lectura negativa, también puede ocurrir que por ello sea, en cada caso, tan solo un hombre fragmentado, parcial, desgarrado, alejado irreversiblemente de la fuente de la lengua primordial. Jean Améry, en un breve ensayo titulado "Das Leben zwischen den Sprachen", señala que el escritor bajo circunstancias de multilingüismo, en principio enriquecedoras y empobrecedoras a la vez, se ve confrontado inevitablemente con aquel sufrimiento que cualquier traductor bien conoce. Subyugado por la lengua, siente cómo la lengua materna, hacia la cual transfiere, se le escurre. A quien está suspendido entre dos lenguas se le presenta un embrollo inextricable, porque las estructuras de las lenguas, en la medida en que resultan distintas, traen consigo, ineluctablemente, diferentes formas del pensar, las que se sobreponen, se entrecruzan y chocan en el traductor. No hay que olvidar que el multingüismo de Goldschmidt, destacado frecuentemente como una de sus fortalezas, no se debe a una adquisición pacífica y armoniosa, sino a la expulsión violenta, el desgarro de la pérdida y el aterrizaje violento en la nueva lengua, áspera y espinosa. Su manera de ingresar e instalarse en el entramado relacional de fuerzas que compone la "lengua secundaria", de manera imborrable lleva la marca de su historia, determinando la manera en que sus incursiones transcurren entre la esperanza y la sospecha, la búsqueda de consuelo y la desconfianza. Por ende, estos intentos por habitar experimentalmente "otra" lengua, portadora de la promesa de encontrar, nuevamente, albergue y cobijo, nunca están a salvo del reencuentro, inevitable y ominoso, con la lengua materna, portadora de la experiencia traumática padecida.

A partir de los años 70, Goldschmidt traduce una serie de obras literarias y filosóficas del alemán al francés: Kafka, Nietzsche, Stifter, Benjamin y otros. La elección de los autores es llamativa: Franz Kafka, que escribe bajo la coerción que ejerce sobre él la voluntad de su padre autoritario al igual que la lengua de éste; Friedrich Nietzsche, filólogo de formación, quizá uno de los escritores de habla alemana más sprachgewaltig, capaz de combinar poder y violencia de la lengua en su decir, que apenas se preocupa por disimular su desprecio por "los alemanes"; Walter Benjamin, traductor de los Tableaux parisiens de Baudelaire, prologada por lo que devendría el célebre "Zur 
Aufgabe des Übersetzers" -que puede ser leído ya sea como "la tarea" o "el abandono del traductor"-, que, en contra del sentido común y del consejo de otros, más circunspectos, se resiste a abandonar Alemania y muere, bajo circunstancias trágicas, en Portbou. Pero el autor al que Goldschmidt más sistemáticamente ha traducido -contando más de 25 textos traspasados al francés- es Peter Handke, lo que ha permitido dar a conocer a este escritor austriaco en los países francoparlantes. Y, a su vez, el propio Handke se ha encargado de traducir algunos de los textos de éste (La forêt interrompue, Le miroir quotidien) al alemán. Otras traducciones de su vasto y diverso øuvre fueron hechas por Brigitte Große, por Eugen Hemlé, por Klaus Bonn y por el propio Goldschmidt, quien, entre otros, más recientemente se ha encargado de traducir al alemán su autobiografía La traversée des fleuves, publicada por la editorial Ammann bajo el título Über die Flüsse (2001). Como era de esperarse, la traducción de Goldschmidt no transcurre en un solo sentido, desde oriente hacia occidente, lo que demuestra su traducción de Alcyon de Pierre Herbart del francés al alemán. Así, los vaivenes entre lenguas, en lugar de someterse a una direccionalidad lineal única, susceptible de ser descompuesta en microrrelaciones causales rectas, demuestran ser múltiples y diversos, llegando a atravesar y entrelazarse en diferentes estratos y cimientos.

En lo que sigue, nos interesa enfocarnos en una "traducción frustrada" -y que justamente implicó su reencuentro con el idioma alemán. En "Freud übersetzen oder wie dasselbe anders aussieht" [Traducir a Freud o cómo lo mismo tiene otro aspecto], Goldschmidt cuenta que "[u]na psicoanalista una vez me invitó a trabajar con su grupo en la traducción de Die Verneinung [La negación] de Sigmund Freud. Transcurridos algunos días, con mucha amabilidad me pusieron de patas en la calle porque me reía en demasía. El intento de trasladar el alemán al francés era tan cómico e inadecuado que a partir de ahí comencé a escribir Quand Freud voit la mer para explicarle al lector francés, desde el mismo interior, cómo se construye el idioma alemán" (2009). Cabe recordar que Goldschmidt era muy amigo de Clara Malraux, la mujer de André Malraux. En 1936, dos años antes de la partida de Goldschmidt a Francia, Clara Malraux, junto con Léon Blum, André Gide y Roger Martin du Gard, entre otros, fundaron el Comité Antifascista, en un intento de advertir a las autoridades francesas del peligro que representaban los crímenes nacionalsocialistas. Siendo, además, una de las primeras traductoras de Kafka, contactó a Goldschmidt con Judith Dupont, editora y traductora de la obra de Freud y de su correspondencia con Ferenczi -la misma Judith Dupont, a la que está dedicado Quand Freud voit la mer. Aparentemente, la traducción 
de Freud al francés - por las razones que fuera- no es compatible con las risotadas. No deja de resultar llamativo que el argumento central del texto en cuestión sea que la lengua permite, por la vía de la negación, que un contenido reprimido advenga a la conciencia como resultado de una operación formal pequeña, a saber, la anteposición de una partícula (un) al elemento troncal de la palabra. Unbewußt, unheimlich, ungeheuer, unsäglich -el vocabulario psicoanalítico, y no tan solo éste, está lleno de ejemplos. La desfiguración o dislocación [Entsetzung], bajo la forma de una alteración combinatoria de las formas de la lengua, aquí aparece en los orígenes del psicoanálisis y del psiquismo, apelando al carácter imperecedero y al potencial productivo, en términos de sintomatología psíquica, del trauma.

Si bien Goldschmidt, por las razones que fuera, no siguió participando de la traducción de Die Verneinung ni de ningún otro texto de Freud, su breve participación en esta instancia habría gatillado la escritura de Quand Freud voit la mer, texto en el cual, primero, muestra cómo el alemán dispone, o pone a disposición, las condiciones de posibilidad del descubrimiento de lo inconsciente; y segundo, exhibe algunas de las dificultades para traducir en general y para el francés en particular al texto freudiano, testimonio del descubrimiento comentado en el primer punto. La relevancia idiomática para la génesis y el devenir del pensamiento de Freud, no obstante, no es un descubrimiento hecho por él, sino algo tempranamente pesquisado. Una prueba aislada de lo anterior es que en 1930 a Freud se le concede el premio Goethe, otorgado por la ciudad de Frankfurt, por su "capacidad de darles figuras [Gestalten] y nombres a los lémures", el resultante "enriquecimiento de la lengua", acompañado "por una interpretación osada de los símiles acuñados por los poetas" (Plänkers 1993: 169). Los trabajos de Walter Muschg, Freud als Schriftsteller (1930), de Walter Schönau, Sigmund Freud. Literarische Elemente seines Stils (1968) y de Walter Jens, Sigmund Freud: Porträt eines Schriftstellers (1990), se han convertido en referentes ineludibles de la discusión acerca de la relación entre Freud y la lengua alemana. Estos trabajos, escasamente traducidos, han quedado recluidos a un grupo de lectores que ya con anterioridad dominaban la lengua de origen -y de destino- $\mathrm{y}$, de algún modo, aplicándoles las mismas tesis enunciadas en los textos aludidos, ya tenían "a mano" o, al menos, a su disposición, las hipótesis ahí enunciadas. El tardío descubrimiento de la heterogénea obra de Georges-Arthur Goldschmidt, entre ellos su Quand Freud voit la mer (1988), acaso pueda cambiar esta situación, que ha hecho obviar la incidencia de la lengua alemana en el psicoanálisis. 


\section{GRAMÁTICA Y SEMÁNTICA DE UN TÍTULO. UNA POLÍTICA DE LA TRADUCCIÓN}

En 1988, la editorial Buchet/Chastel publica Quand Freud voit la mer. El texto, lejos de conformar una excepción, pues se inscribe en una tradición inaugurada por Wilhelm von Humboldt y Johann Gottfried von Herder, luego proseguida por Arthur Schopenhauer y Friedrich Schleiermacher, aborda una problemática ya mencionada: el problema del traducir y la relación entre lengua y pensar. Justamente porque la diversidad [Verschiedenheit] de la complexión o constitución [Beschaffenheit] de las lenguas es una diversidad de las cosmovisiones o concepciones de mundo, la tarea de ir más allá, de trasgredir y despolitizar la lengua materna y la subsecuente comparación de las lenguas entre sí, es un imperativo ineluctable para cualquier pensador, y con mayor razón, para un ciudadano de la Europa del siglo XX. El libro tardó once años en ser traducido al alemán y, según Goldschmidt comenta en una entrevista, se trata, a grandes rasgos de una autotraducción o traducción de sí, asistida por Brigitte Große. Esto no deja de ser interesante, considerando que ya en la introducción del libro Goldschmidt desmiente uno de los más consolidados prejuicios lingüísticos, ennoblecido y elevado a dictamen interrogable por el "filósofo del Hotzenwald", a saber, el hecho de que el alemán, la lengua del "pueblo de los poetas y pensadores, suspendidos y visionarios", sería una lengua predilecta, que predispone, de manera absolutamente excepcional y extraordinaria, como tan solo el griego habría podido, a la reflexión filosófica. En una conferencia ya citada, titulada Comment traduire a Freud où comme le même devient autre, Goldschmidt denuncia cómo todo el siglo XIX habría vivido con la idea que alemán es la lengua de las lenguas, que sería la lengua de la autenticidad [Eigentlichkeit], según el invento trasnochado de a quien él denomina "el infeliz criminal de Freiburg". La Eigentlichkeit, l'autenticité, la toma de posesión, la propiedad, verdadera y real, inherente al alemán, convierte a éste en la única lengua en la que las cosas se pueden decir con propiedad y, por consiguiente, en la única lengua. De ahí, prosigue Goldschmidt, la tan desafortunada y errónea leyenda del alemán como la única lengua de la filosofía. A diferencia de este planteamiento aristocratizante, impregnado por el clima de su época, entrampado en el intento de corroborar la superioridad (originalidad, autenticidad, idoneidad) de una lengua particular por sobre las demás, habría que asumir, más bien, que toda lengua es tan filosófica -o tan poco filosófica- como cualquier otra. La propuesta de Barbara Cassin de un Dictionaire des intraduisibles, se sostiene en la misma tradición que 
Goldschmidt: antes que un "Es gibt Sein", un "Il y a de langues" (Cassin 2016, p. 49). Sobre este "hay", que equivale a un compromiso político intransable, descansa el planteamiento de Goldschmidt.

Apenas aparecida la primera edición del libro en alemán, en 1999, Ludger Luetkehaus, autor de Dieses wahre innere Afrika. Texte zur Entdeckung des Unbewußten vor Freud (1993) y Freud zum Vergnügen (2012), en un artículo publicado en Die Zeit, titulado "Welche Sprache spricht das Unbewusste?" repara en la intraducibilidad del título. El quand francés, recuerda Luetkehaus, podría traducirse como wenn, es decir, una forma condicional: "sí" o "cuando". Wenn Freud das Meer sieht, "Si Freud ve el mar" -y uno espontáneamente se siente tentado de añadir "entonces...", "ergo...". En dicha traducción se mantiene el tiempo presente del voit, pero empleando un wenn iterativo en lugar del quand francés. El título impreso, la lengua escrita, obliga al uso, más correcto, más formal, de als en vez de wenn y, como su consecuencia, exige el uso del pretérito: Als Freud das Meer sah, "Cuando Freud vio la mar". Al menos en alemán, el título gana en corrección gramatical, pero pierde en poeticidad y sugestividad. En una entrevista publicada en la revista Rezenszeitschrift für Literaturübersetzungen, Goldschmidt dirá que el título en francés es "so vage", es decir, es tan vago, tan impreciso, mientras que la alternativa literal en alemán, "gar nicht geht", simplemente no funciona, de ningún modo. En sus propias palabras, él quería algo que pusiera en relación a Freud y el mar y, según confiesa, simplemente habría sido demasiado flojo, perezoso, vago (ahora utilizado en otro sentido), "faul", para pensar en otra cosa. Insiste en que en el traspaso de mer a Meer, que a primera vista parece directo e inapelable, se sacrifica la insinuación de un doble sentido, a saber, entre mer (Meer, mar) y mère (Mutter, madre), un juego lingüístico decididamente intraducible. No obstante, en la lengua alemana, la homofonía entre Meer y mehr [más], abre otras posibilidades que apuntan, por ejemplo, hacia el aumento, la ampliación o el acrecentamiento. Es la madre, el primer objeto de amor del niño, la que es dejada atrás, la que no es hecha desaparecer activamente, y tal como sucedería en el célebre Fort$D a$, sino que es perdida como resultado de una separación forzosa en cuyo transcurso el joven Georges-Arthur toma un tren en dirección primero a Italia y luego a Francia, mientras que la madre, al lado del padre, permanece parada en el andén. Lejos de condensarse únicamente en el título, todo el libro se encuentra atravesado por la cuestión de cuándo y cómo Freud no tan solo contempló, sino que supo escuchar la mar y sus múltiples metáforas, imprimiéndole un ritmo, una cadencia, un compás conformado por el continuo 
balanceo de la marea. Mostrándose sensible a dicha proximidad, la traducción alemana rescata esta cuestión cada vez que puede, desentendiéndose hasta cierto punto del original, incluso haciendo emerger el mar ahí donde no estaba. Así, por ejemplo, cuando en francés se habla de le fil de la langue, una expresión empleada en reiteradas ocasiones por el autor, en alemán se opta por decir die Fluten der Sprache, las mareas, los flujos, las corrientes de la lengua. Esta elección corre en paralelo y se refuerza mutuamente con la concepción de las lenguas como organismos pulsionantes, seres vivos que poseen todas las características de la pulsión [Trieb] -no solamente sus cuatro elementos constituyentes (fuente, esfuerzo, meta y objeto), sino sus propiedades y rasgos distintivos, en particular, su carácter dinámico, fluido, o mejor, fluyente, líquido, acuoso, corriente. Es decir, la mar ya siempre está en todas partes, todo lo inunda, todo lo colma, convirtiéndose en medium, líquido y acuoso, en el cual puede constituir y perpetuarse el deseo. Lejos de conformar un hábitat quieto y estático, instaura un dominio dinámico y plástico, compuesto por múltiples corrientes y contracorrientes, que le abren paso y jalonean al despliegue del psiquismo. Sin embargo, más allá del juego de las fuerzas vectoriales de cada lengua, que a su manera intentan encubrir el hecho de que están estructuradas en torno a una falta, una imposibilidad de decir, insiste, en la travesía de Goldschmidt, el abismo insondable que separa dos lenguas entre sí, aquel punto ciego que sostiene la imposibilidad de una correspondencia perfecta -y que, en última instancia, opera como el motor del decir. El que Trieb no sea el instinto, pero tampoco la pulsión, es quizá el mejor ejemplo para ilustrar que una lengua, en virtud de sus trazos significantes, pueda expresar lo no-dicho, o incluso lo indecible, de otra.

\section{DISCUSIÓN}

En resumen, la obra de Goldschmidt, más allá de su heterogeneidad constituyente, se distingue por su relación con la traducción y ello en varios sentidos: para comenzar, su trayecto biográfico, que va desde Alemania hacia Francia y viceversa, en primera instancia sufrido pasivamente, lo ubica en el lugar del padeciente, de quien experimenta una fuerza ajena que se despliega a partir de lo presuntamente propio, la lengua materna, que opera sobre él, sin posibilidad de resistirse a la ex-pulsión, condenado a dejarse flotar, a mecerse en el retozo de las mareas, treiben; este primer momento, que ha sido caracterizado como un instante de sujeción a la lengua, constituye el 
antecedente para un segundo instante, aquel de habitar una lengua que no es la propia y que, sin embargo, se ofrece como un espacio susceptible de convertirse en morada. Sin que con esto se quiera sugerir que las peripecias y tribulaciones del personaje biográfico de carne y hueso se transcriban linealmente en su obra, ni que la psicobiografía del autor, una figura polémica, no libre de complicaciones, sea una vía de acceso a la comprensión de su escritura, no obstante, la travesía anteriormente descrita ilustra el paso de un espacio lingüístico a otro $-\mathrm{y}$ las respectivas sujeciones a las cuales el hablante queda sometido en cada uno de ellos. En ese sentido, cuando se afirma que Georg se convierte en Georges, hacemos alusión no a las determinaciones lineales que recaen en el sujeto Goldschmidt, ya previamente constituido, y que conforman un sujeto provisto con determinadas características, sino que apuntamos a que las potenciales vías de assujettissement son dibujadas en cada caso dependiendo de los potenciales de resistencia y de facilitación de cada lengua. Más allá de las determinaciones estructurales sufridas por su inscripción -mítica, pues no sucede en un momento histórico determinable, siempre alienante pues acontece en un medio de mediaciones- en el lenguaje, la subjetivación se perfila en cada lengua de manera singular e irrepetible. En el caso de Goldschmidt, dicho proceso bimembre, conformado tanto por la constitución o el emplazamiento, la posición [Setzung] del sujeto como por sus gestos autoemancipatorios, opera sobre el antecedente de las grietas y fisuras, producidas en su tejido lingüístico, producto del trauma padecido, montadas sobre la enajenación primordial padecida a través de la mentada inscripción en el lenguaje. A la diferencia entre lenguaje y lengua, que supone coerciones y posibilidades en cada caso distintas, hay que sumarle la diferencia entre dos lenguas, el alemán y el francés, que supone la opción de retornar, por la vía del desvío, sobre lo mismo, produciendo una supraposición o transposición, en otras palabras: una traducción [Übersetzung]. Queda en suspenso, en este lugar, la pregunta por una tercera lengua, acaso hipotética, capaz de que efectivamente se efectúen los tránsitos anteriormente descritos y no se traduzcan en sumisión absoluta a la mecánica autoritaria de la transcripción o en mera arbitrariedad, tan caprichosa y violenta como la primera posibilidad.

En segundo lugar, las inserciones de Goldschmidt en la lengua, siempre transitorias, siempre efímeras, realizadas contingentemente en plexos lingüísticos diversos y cambiantes, determinados por ciertas propiedades estructurales, y sus respectivas dislocaciones y exclusiones de la lengua respectiva en la que se esforzaba, se realizaban principalmente mediante la escritura -más allá de su género, formato o pertenencia disciplinar. En sus textos se pone 
en juego la posibilidad de un rodeo y de una simultánea toma de distancia del acontecimiento traumático, ligado inextricablemente a la lengua materna, convertida en la lengua de los asesinos, a través del recurso, primero, a una lengua otra en general, una lengua extranjera, y segundo, a una lengua cuya característica sería, según subraya el propio Goldschmidt, la de ser menos inmediata, más centrada, justamente, en las mediaciones construidas racionalmente. La elaboración escritural de la experiencia personal del autor, lo primero, y la operación autotraductiva en un segundo, giran sobre el pivote innombrable conformado al trauma. El gesto aquí es enrevesado en varios sentidos: vuelve sobre un texto propio, portador del trauma constituyente, que se muestra como su afuera inasimilable, produciendo un efecto de duplicación de este núcleo inasimilable, suerte de ombligo del texto; segundo, la torna sobre el texto implica, a su vez, un retorno de la lengua, de aquella lengua que justamente había expulsado al sujeto hablante, convirtiéndose en no man's land hostil e inhabitable.

Esto se vuelve particularmente patente en el otro texto, aparte de Quand Freud voit la mer, traducido por el mismo Georges-Arthur Goldschmidt: La Traversée des fleuves, originalmente publicada en 1999, que sería publicado en alemán dos años después como Über die Flüsse (2001). Podría decirse que en este texto convergen con particular nitidez elementos autobiográficos con aspectos teóricos vinculados a la reflexión sobre el problema de la traducción, convirtiéndolo en un texto clave, una bisagra entre dos formatos, géneros y corrientes en principio distintos. Über die Flüsse, "sobre los ríos", alusión al paso sobre los ríos fronterizos, que delimitan dos países, dos comunidades hablantes, como es ilustrado en el caso del shibboleth, como a las respectivas aguas de las lenguas, sus flujos y corrientes -o, más precisamente, señalamiento del über, sobre, partícula que integra tanto el übersetzen, traducir, como el Übermensch, el super, supra o transhombre nietzscheano, como la Überdeterminierung, la sobredeterminación. Pero también resuena überflüssig, superfluo, sobrante, también innecesario, o más literalmente: aquello que desborda, überfließen, lo que fluye por sobre - un borde, un límite, una frontera. En todo caso, el empleo de la metáfora de las aguas, del entre dos aguas es casi un lugar común en toda reflexión sobre traducción, que en este caso se plasma en las ideas de las corrientes superadas y por superar. En la novela en cuestión, como ha destacado Rainer Guldin (2007), el autor, que en ella narra su propia vida -o, también, lo más impropio en su vida, lo inasimilable-, escribe por primera vez en primera persona singular. En el prefacio, Goldschmidt explicita una convicción singular, que no necesariamente coincide con las tendencias más 
recientes en el campo de la traducción, al decir que se trata de que "siga siendo el mismo texto. También se trata de que el texto no sea remodelado o transformado [umgestaltet] por la otra lengua. Por esto se tradujo tan exactamente, tan fiel a la palabra como posible, sin desviarse del texto. Los casos contados en los cuales esto sucedió son señalizados por notas al pie" (2001: 7). Y sin embargo, como ha de admitir el propio auto(r)-traductor, a pesar de todo esfuerzo por mantener la identidad del texto, por evitar que se transforme en otro, el sonido y las representaciones, propias de cada lengua, inevitablemente operaron sobre el texto, al margen de la conciencia y a pesar de la voluntad del intérprete. Se constata, no solo en este lugar, una brecha entre las proclamaciones explícitas, en este caso antepuestas al texto, y la praxis traductiva efectual. Traducción, tanto como escritura, resultan ser dos operaciones no subsumibles ni exclusiva ni enteramente al ámbito de la conciencia y de la voluntad racional. Más bien pareciera ser que lo crucial de la traducción guarda relación con las manifestaciones inconscientes, con la producción puntual y esquiva, que transcurre a espaldas y al margen del dominio de la conciencia. A pesar de la exigencia del respeto por un texto original, coherente en sí, traducible, la demanda de reproducir absolutamente el tono del original, se abre un espacio intersticial entre esta declaración de buenas intenciones y el quehacer del traducir propiamente tal. Guldin ha demostrado como la exigencia literal, declarada e impuesta al inicio del texto, es contrariada y finalmente frustrada, una y otra vez, por decisiones tomadas ad hoc. La traversée se inscribe justamente en la hendidura infranqueable entre ambas lenguas; y dicha inscripción no es única, simple, sino doble: en tanto autobiografía bicultural y reflexión práctica sobre la traducción.

La travesía de Goldschmidt, al mismo tiempo rigurosa y sujeta a decisiones contingentes, espontáneas, acaso azarosas, se opone a cualquier jerarquización de lenguas, le quita el piso a toda argumentación orientada a establecer la superioridad u originalidad de una lengua sobre otras. Más bien, ilustra la necesidad de seguir al pie de la letra, literalmente, y a contrapelo, el discurrir de la lengua, siguiendo un recorrido fronterizo entre zonas idiomáticas, entre formatos escriturales. Y en ello consiste su audacia y valor.

\section{BIBLIOGRAFÍA}

Altwegg, Jürg. "Josef K., das war ich”. Frankfurter Allgemeine Nr. 261: 34. 07.11.2008, Améry, Jean. "Das Leben zwischen den Sprachen". Zeit, nr. 37, 3. September, 1976, www. zeit.de/1976/37/das-leben-zwischen-de-sprachen/komplettansicht 
Claro, Andrés. "El contrato de transporte y el naufragio del sentido: las concepciones lingüísticotrascendentales de W. von Humboldt". Grifo 21 (2011): 19-23.

Las vasijas quebradas. Cuatro variaciones sobre "la tarea del traductor". Santiago: Universidad Diego Portales, 2012.

Cassin, Barbara. La nostalgia ¿Cuándo es que, por fin, uno está en su hogar? Ulises, Eneas, Arendt. Buenos Aires: Nueva Visión, 2013.

Éloge de la traduction. Compliquer l'universel. Paris: Fayard, 2016.

Freud, Sigmund. "Pulsiones y destinos de pulsión". En S. Freud, Obras completas de Sigmund Freud: Contribución a la historia del movimiento psicoanalitico: Trabajos sobre metapsicología y otras obras:1914-1916 (J. L. Etcheverry, Trad., 2ª ed., Vol. XIV, pp. 105-134). Buenos Aires: Amorrotu, 2010d.

"Lo ominoso". En S. Freud, Obras completas de Sigmund Freud: De la historia de una neurosis infantil (el "Hombre de los Lobos") y otras obras: 1917-1919 (J. L. Etcheverry, Trad., $2^{\mathrm{a}}$ ed., Vol. XVII, pp. 215-251). Buenos Aires: Amorrortu, 2007c.

"Fetichismo". En S. Freud, Obras completas de Sigmund Freud: El porvenir de una ilusión. El malestar en la cultura y otras obras: 1927-1931 (J. L. Etcheverry, Trad., $2^{\mathrm{a}}$ ed., Vol. XXI). Buenos Aires: Amorrortu, $2007 \mathrm{~b}$.

"El olvido de los nombres propios". En S. Freud, Obras completas de Sigmund Freud: Psicopatología de la vida cotidiana: 1901 (J. L. Etcheverry, Trad., 2ª ed., Vol. VI, págs. 9-15). Buenos Aires: Amorrortu, 2007a.

Goldschmidt, Georges-Arthur. "Comment traduire a Freud où comme le même devient autre", conferencia impartida ante la Schweizer Gesellschaft für Analytische Psychologie (SGAP) en su Congreso anual 9 y 10 de marzo 2009, www.sgap.ch/SGAP_neu/downloads/T_ Goldschmidt_Comment traduire a Freud.pdf

“Una chambre à deux dossiers / Ein Stuhl mit zwei Lehnen", Sirene 4/8 (1991): 68-99.

Cuando Freud vio la mar. Santiago: Metales Pesados, 2017.

Der Stoff des Schreibens. Berlin: Matthes und Seitz, 2005.

Quand Freud attend le verbe. Paris: Buchet/Chastel, 1996.

Über die Flüsse. Autobiographie. Zürich : Ammann, 2001.

Guldin, Rainer. “'Das sonderbare Francodeutsch'. Georges-Arthur Goldschmidt: Übersetzer und Selbstübersetzer", En Georges-Arthur Goldschmidt: 1/09 Text und Kritik, ed., by H. L. Arnold, 181, München 2009, pp. 59-70.

"Verschiedene Wege zum selben Ziel. Zur Bilingualität im Werk Georges-Arthur Goldschmidts". Kultur und Gespenster 5 (2007): 102-119.

Hartwig, Ina. "Direkt in die Talschlucht hinein. Georges-Arthur Goldschmidt im Gespräch". Frankfurter Rundschau, Ausgaben D/R/S, 29, 2.2 (2001): 17-22.

Das Geheimfach ist offen: Über Literatur. Frankfurt a. M.: Fischer, 2012.

Holdenried, Michaela. "Das Ende der Aufrichtigkeit? Zum Wandel autobiographischer Dispositive am Beispiel von Georges-Arthur Goldschmidt". Archiv für das Studium der neueren Sprachen und Literaturen 1/149 (1997): 1-19. 
Lacan, Jacques. El seminario. Libro 6. El deseo y su interpretación. Buenos Aires: Paidós, 2007.

Lamping, Dieter. "Die literarische Übersetzung als dezentrale Struktur: Das Paradigma der Selbstübersetzung”. Übersetzung, Bd. 5 (1992): S. 212-227.

"Linguistische Metamorphosen". Aspekte des Sprachwechsels in der Exilliteratur. En Hendrik Birus (ed.). Germanistik und Komparatistik (528-540). Stuttgart, Weimar: J. B. Metzler, 1995.

Muschg, Walter. "Freud als Schriftssteller". Die psychoanalytische Bewegung 2, Heft 5, (1930): 467-509.

Plänkers, Tomas. "Vom Himmel durch die Welt zur Hölle": zur Goethe-Preisverleihung an Sigmund Freud im Jahre 1930. En Jahrbuch der Psychoanalyse: Beiträge zur Theorie, Praxis und Geschichte, tomo 30 (1993): 167-181.

Rector, Martin. "Frühe Absonderung, später Abschied. Adoleszens und Faschismus in den autobiographischen Erzählungen von Georges-Arthur Goldschmidt und Peter Weiss". Peter Weiss Jahrbuch 4 (1995): 122-139.

Schönau, Walter. Sigmund Freud. Literarische Elemente seines Stils. Gießen: Psychosozial Verlag, 1968.

Walter Jens. "Sigmund Freud: Portät eines Schriftstellers”. Psyche 191 (1990): 949-966.

Willer, Stefan. "Selbstübersetzungen. Georges-Arthur Goldschmidts Andersprachigkeit”. En S. Arndt, D. Naguschewski, R. Stockhammer (eds.), Exophonie. Anders-Sprachigkeit (in) der Literatur (264-281). Berlin: Kadmos, 2007. 